\title{
Carnap, Friedman e o ReVisionismo
}

\author{
GELSON Liston
}

\begin{abstract}
In this article we will analyze the work of Carnap in order to re-evaluate a period of philosophy of science whose influence can still be detected in current research of an empiricist orientation and should not be filed away simply as an object of historical research or literary nostalgia. We will evaluate the proposal of a revisionist reading of Carnap, in particular by Friedman, and we will conclude by articulating a minimalist position of Carnap's philosophy, identified with the logic of science and concerned with the empirical interpretation of scientific language.
\end{abstract}

Keywords: Carnap; Friedman; revisionism; philosophy of science; empiricism

\section{Introdução}

Neste artigo, analisaremos a importância de retomar a obra carnapiana não apenas enquanto um trabalho historiográfico, mas também como uma forma de revalorizar um período da filosofia da ciência cuja influência ainda pode ser notada nos trabalhos atuais. Pretendemos, com isso, avaliar a importância da leitura feita pelos revisionistas de Carnap e do positivismo lógico; em especial a leitura proposta por Friedman. Reconhecemos, portanto, o valor da análise por ele feita, pois ela nos auxilia a ver que um trabalho desta natureza continua tendo importância nas discussões atuais em torno do tema 'filosofia da ciência', e, sobretudo, da filosofia analítica póspositivista. Nossa posição para tal incursão parte do pressuposto de que a filosofia da ciência de cunho empirista, de Carnap, não foi apenas um momento na história da filosofia, um episódio cristalizado por seus historiadores e completamente superado por seus sucessores de orientação empirista ou realista.

A nosso ver, não se trata de um arquivo morto. Tampouco concordamos com a expressão de Isaac Levi, quando se refere à vitória do realismo científico: "minha própria concepção é de que o caixão do empirismo está devidamente lacrado", citada por van Fraassen (2006, p.21), e com a posição do próprio van Fraassen (2006, p.18) em relação ao positivismo lógico: “[...] ainda que se possa ser bastante caridoso sobre o que ele representa como desenvolvimento, e não como tomada de posição, teve um fracasso bastante espetacular". Embora concordemos que o positivismo lógico tenha apresentado inúmeros problemas, não nos parece sustentável a afirmação de que tal movimento filosófico, tão influente na filosofia analítica do século XX, seja hoje reconhecido apenas por seu fracasso.

Principia 17(1): 137-164 (2013).

Published by NEL — Epistemology and Logic Research Group, Federal University of Santa Catarina (UFSC), Brazil. 
Mesmo que o positivismo lógico seja considerado ultrapassado, autores como Boyd e van Fraassen, curiosamente, ${ }^{1}$ se dão ao trabalho de criticá-lo e de tentar resolver melhor que ele problemas que dele herdaram, como o da unidade da ciência, da observabilidade e da interpretação da linguagem científica. Ainda que Carnap tenha exagerado em sua compreensão e concepção linguística do conhecimento científico, a linguagem continua sendo um instrumento fundamental na interpretação de teorias científicas, embora, é claro, com outras perspectivas, como é o caso da interpretação semântica de van Fraassen. ${ }^{2}$

É sintomático, entretanto, que uma perspectiva considerada "ultrapassada" por importantes filósofos da ciência atuais, como Boyd e van Fraassen, esteja tão presente na reflexão destes últimos. Retornando ao tema das críticas a Carnap, o que podemos supor é que, mais que um esforço (agora desnecessário) de refutação das teses de Carnap, o que elas mostram, tais críticas, é o quanto a filosofia da ciência atual deve à obra de Carnap. ${ }^{3}$

Em uma posição claramente diferenciada, Michael Friedman 1999 retoma algumas teses centrais da obra de Carnap com o objetivo de reconsiderar o positivismo lógico enquanto um movimento que teve um papel fundamental na filosofia do século $\mathrm{XX}$, cujos resultados não podem simplesmente serem arquivados à título de pesquisa histórica ou de simples nostalgia literária. Nesse sentido, nossa proposta tenta mostrar que um dos principais objetivos de Carnap, sobretudo expresso em seu princípio de tolerância linguística, é articular um método de resolver ou dissolver disputas e perplexidades filosóficas relativizando-as a um sistema linguístico de referência. Deste modo, concordamos com Friedman (cf. 1999, p.211) que a obra de Carnap, pautada no princípio de tolerância linguística, apresenta um novo método à filosofia, sobretudo ao que hoje chamamos de filosofia da ciência.

Entendemos que as alterações promovidas por Carnap, desde o Aufbau, não representam uma ruptura em seu trabalho filosófico, mas mudanças que devem ser analisadas pelo viés da objetividade científica e da reformulação/liberalização do empirismo, e não por uma atitude declaradamente antifundacionalista, ${ }^{4}$ que surge como consequência do fracasso na busca de sentenças observacionais definitivas para formar a base de certeza da construção do conhecimento científico. Podemos afirmar que já no Aufbau Carnap trabalha com o princípio de tolerância linguística, a saber, a posição em relação à escolha da linguagem do sistema, formulada como princípio de tolerância em 1934, ${ }^{5}$ é uma característica de toda sua obra (cf. Carnap 1963a, p.18), e com uma posição neutra em relação à construção da linguagem da ciência, sem qualquer compromisso ontológico, que, segundo Carnap, é a função da filosofia. Carnap identifica a filosofia com a análise lógico-linguística. Uma das consequências dessa identificação é que a filosofia não pode ser comparada a um sistema de enunciados que permita a formulação e defesa de teses, nem tampouco estabelecer proposições próprias. Portanto, não há ruptura, mas a continuidade de um projeto que 
sofre alterações previstas em seu plano inicial. Tais mudanças podem ser vistas - e criticamente analisadas - como um desenvolvimento, como aperfeiçoamento de um sistema que não pretende ser ideal, mas efetivo e racional. Ressaltamos, aqui, que a escolha da base do sistema, com pretensões de unidade científica, é convencional e que o objetivo principal, portanto, é mostrar que um sistema construcional, onde todos os enunciados científicos possam ser construídos, é possível. Assim, a escolha da base é secundária, embora Carnap tenha apresentado uma justificativa epistêmica para a escolha da base fenomenalista no Aufbau: primazia epistêmica. Em sua autobiografia intelectual, Carnap retoma essa discussão e afirma que a escolha de tal base é uma questão prática — um modo de falar — frente a várias formas de linguagens, sustentada pelo princípio de tolerância linguística. Desse modo, não há uma via correta ou incorreta na escolha de um sistema de linguagem para a ciência, mas uma questão de ser mais, ou menos eficiente e útil naquilo que se propõe. Portanto, uma questão pragmática externa.

Se estivermos corretos em nossa interpretação, então a filosofia científica de Carnap continua sendo uma referência para o empirismo contemporâneo, pois seus erros, apontados e superados por Carnap - sobretudo o reducionismo fenomenalista - estão em segundo plano. O que permanece, portanto, é seu sistema enquanto uma forma de expressão linguística: uma referência para os conceitos significativos e para a dissolução de disputas fundamentadas em pseudoproblemas filosóficos. A tese central de que o conhecimento científico pode ser reconstruído e unificado a partir da linguagem lógica, ${ }^{6}$ é constante na obra de Carnap.

Portanto, nossa hipótese, seguindo a posição de Friedman, é que Carnap, muito mais que apresentar um relato tradicional empirista fundacionalista do conhecimento no Aufbau, ele antecipa a estratégia (E.S.O.) de construir uma linguagem científica compatível com o empirismo e que pretende eliminar as discussões filosóficas indecidíveis por não serem relativizadas a uma estrutura linguística. Vejamos a posição de Friedman:

Deste modo, muito mais que apresentar um relato tradicional empirista, ou
fenomenalista do nosso conhecimento do mundo externo, o Aufbau, por sua
vez, antecipa a estratégia de Carnap em 'Empiricism, Semantic, and Onto-
logy': a questão da realidade do mundo externo é dissolvida em 'questões
externas', ou seja, se deve, ou não, ser aceita e usada na forma de expres-
são da 'linguagem objeto'. Assim sendo, uma 'questão externa' não está,
naturalmente, sujeita à disputa racional como um todo, mas apenas às con-
siderações convencionais puramente pragmáticas. (1999, p.124).

As questões externas não passam de pseudoproblemas quando tratadas como questões teóricas e não como questões práticas ou de decisões pragmáticas, entendidas como escolhas linguísticas. Essa atitude tolerante de Carnap na escolha da 
linguagem da ciência rumo a um "oceano aberto de ilimitadas possibilidades" ou modos de falar (cf. Carnap 1934, p.xv), será aqui ressaltada.

\title{
2. Tolerância e sistema linguístico de referência
}

O empreendimento de reconstrução racional do conhecimento científico, realizado por Carnap, tinha como objetivo principal a unificação do conhecimento científico e, como um segundo objetivo, ou ainda uma consequência do objetivo principal, a eliminação da metafísica. Não se trata, portanto, da defesa de uma tese antimetafísica, mas, antes, da construção de uma linguagem científica unificada com um propósito muito claro: a unificação racional do conhecimento científico. Carnap sempre se posicionou de forma contrária a qualquer discussão ou disputa metafísica, o que justifica sua neutralidade:

\begin{abstract}
Não consigo pensar em nenhuma evidência possível que ambos os filósofos considerariam como relevante e que, portanto, se fosse descoberta, decidiria a controvérsia ou pelo menos tornaria uma das teses opostas mais provável do que a outra. (Construir os números como classes ou propriedades do segundo nível, segundo o método de Frege-Russell, não resolve, obviamente, a controvérsia, porque o primeiro filósofo afirmaria e o segundo negaria a existência do sistema das classes ou propriedades do segundo nível). Portanto, sinto-me compelido a considerar a questão externa como pseudoquestão, até que ambos os lados da controvérsia ofereçam uma interpretação comum da questão enquanto questão cognitiva; isso envolveria uma indicação da evidência possível considerada relevante por ambos os lados. (Carnap 1975a, p.126)
\end{abstract}

Parece-nos importante analisar a função de um sistema linguístico de referência na distinção entre ciência e metafísica, o que permite o uso do termo 'realidade' sem qualquer compromisso ontológico-metafísico. No Aufbau, o termo 'real' era usado para designar um objeto que fazia parte do sistema construcional, ou seja, um objeto pode ser dito real se tiver como referência um sistema linguisticamente estabelecido. Em Pseudoproblemas na Filosofia, ${ }^{7}$ ao tratar desta questão, Carnap atribui significatividade aos enunciados (empíricos) que expressam um estado de coisa real ou concebível, e mostra que a controvérsia entre realistas e idealistas ${ }^{8}$ é um problema externo à ciência, pois a discussão está para além do domínio empírico, impossibilitando qualquer decisão que possa ser racionalmente considerada.

Em outra obra, Filosofia e Sintaxe Lógica, os argumentos de Carnap seguem na mesma direção e se fundamentam na possibilidade de uma investigação empírica capaz de dizer sim ou não (verdadeiro ou falso) se o problema for científico (significativo):

Principia 17(1): 137-164 (2013). 
Quando um zoólogo afirma a realidade dos cangurus, sua afirmação significa que existem coisas de um certo gênero que podem ser localizadas e percebidas em determinados tempos e lugares; que há objetos de um certo tipo que são elementos do sistema espaço-temporal do mundo físico. Esta afirmação, de fato, é verificável; através de investigações empíricas, todo zoólogo chega a uma efetiva verificação, independentemente de ser um realista ou um idealista. (Carnap 1963c, p.12)

A grande importância da sintaxe lógica, independentemente da fase verificacionista ou da fase confirmacionista, deve ser vista a partir da atitude antimetafísica do Círculo de Viena. Para Carnap, a filosofia é a sintaxe lógica da linguagem e, como as controvérsias metafísicas têm como causa problemas meramente linguísticos, partiremos de uma distinção que nos parece ter uma importância fundamental para a construção da filosofia científica e para a unidade da ciência, uma vez que esta se sustenta em uma linguagem universal. Trata-se da distinção estabelecida entre linguagem-objeto e metalinguagem. É isso o que Carnap faz em A Sintaxe Lógica da Linguagem (p.4), onde a linguagem-objeto é definida como a linguagem que é objeto de nossa investigação, e a metalinguagem (linguagem sintática), a linguagem que possibilita a discussão sobre as regras sintáticas da linguagem-objeto. Essa hierarquia de linguagens possibilita o uso de uma determinada linguagem para falarmos de expressões formadas na mesma linguagem.

Com esta distinção, o método sintático tem uma função importante na solução de problemas filosóficos, pois estes não deveriam ser colocados na forma da linguagemobjeto, mas formulados na metalinguagem, na qual encontrariam solução. Disso podemos inferir que os problemas filosóficos são problemas sintáticos e que a filosofia é a própria sintaxe lógica.

A formulação precisa dos problemas filosóficos foi a principal motivação para o desenvolvimento do método sintático que, a partir da construção de uma estrutura linguística, possibilita a relativização destes a tal estrutura, eliminando ou destituindo a controvérsia filosófica. ${ }^{9}$ Deste modo, os problemas filosóficos são puramente linguísticos. Por essa razão, "a lógica da ciência toma o lugar das inextricáveis confusões de problemas conhecidos como filosofia" (Carnap 1934, p.279). Assim prossegue Carnap dizendo que, para os objetivos de qualificação científica, tudo o que permanece da filosofia é a lógica da ciência.

Aqui, a identificação da filosofia com a sintaxe lógica da linguagem surge como consequência de duas teses afirmadas por Carnap (1934, p.281):

(a) A filosofia é a lógica da ciência.

(b) A lógica da ciência é a sintaxe da linguagem da ciência.

Entretanto, como adverte Carnap (1934, p.322), a tese de que a lógica da ciência é a sintaxe não deve ser interpretada como um tema completamente fora do campo 
da ciência empírica: como algo puramente formal, uma vez que a linguagem da ciência não se apresenta de um modo sintaticamente estabelecido. O método é lógico, mas a finalidade é analisar a linguagem científica, que, por sua vez, depende de algo extralinguístico.

Ao tratar da sintaxe enquanto método de filosofar, Carnap, em Filosofia e Sintaxe Lógica, apresenta uma definição cuja análise nos parece extremamente importante para compreendermos o caráter e a função do discurso formal, em vista dos problemas gerados pelo discurso, ou modo material. No modo material de falar a relação entre os conceitos é imprecisa se comparada à relação conceitual do modo formal. Assim, a sintaxe lógica é entendida como a teoria formal da linguagem — a metalinguagem.

Com a utilização do modo formal de falar, os problemas filosóficos metafísicos são evitados, e muitas confusões filosóficas resolvidas, pois as questões são analisadas a partir de um determinado sistema de linguagem. Assim, o caráter enganoso do modo material de falar é superado, uma vez que os enunciados passam a ser relativizados em relação a um sistema de linguagem definido.

O método de tradução, do modo material para o modo formal, que propõe a solução de problemas originados na própria formulação de sentenças, tem como consequência facultar a liberação da análise lógica à referência de objetos extralinguísticos, ou seja, a análise se dá em um sistema puramente linguístico. Contudo, Carnap chama a atenção para um ponto central de nossa discussão, ao enfatizar que tal conclusão é própria da análise lógica, ou seja, da investigação metalinguística, mas que nas ciências empíricas a referência aos objetos se dá de modo efetivo, de acordo com o sistema espaço-temporal, onde as questões são decidíveis (cf. Carnap 1963c, p.45). Ao utilizarmos o termo 'impossibilidade', por exemplo, seu sentido dependerá do sistema de referência, seja este lógico ou físico.

Muitas controvérsias filosóficas são causadas pela falta de uma referência linguística, o que demonstra a incompletude das teses filosóficas;

Muito frequentemente, surgem controvérsias filosóficas fúteis em razão da incompletude das teses. Essa incompletude se esconde na própria formulação usual do modo material; quando traduzidas para o modo formal, nota-se imediatamente a carência de referência a uma linguagem. Então, mediante o acréscimo de tal referência, as teses se completam e, por conseguinte, as controvérsias se tornam claras e exatas [...] A relatividade de todas as teses filosóficas em consideração à linguagem, isto é, a necessidade de referência a um ou mais sistemas de linguagem particulares, é um ponto essencial a que se deve prestar atenção. Tal relatividade quase sempre passa despercebida devido ao uso geral do modo material de falar. (Carnap 1963c, p.48)

Daí a relevância do princípio de tolerância no que diz respeito às formas linguísticas, o que não é o caso das sentenças empíricas que dispõem de um sistema único 
de referência. $\mathrm{O}$ uso do modo material ${ }^{10}$ de falar leva-nos a desconsiderar a relatividade das sentenças filosóficas a uma linguagem. É deste modo que surge a maioria das controvérsias filosóficas (linguísticas), ou seja, pseudoteses do modo material de falar. Contudo, em momento algum, Carnap defende a eliminação do modo material de falar, já que este é um elemento importante do uso linguístico ordinário. Todavia, na construção de uma linguagem científica, livre de ambiguidades, este artifício linguístico pode ser perigoso, exigindo, deste modo, uma atenção especial quanto ao seu uso, no sentido estrito de evitá-lo, não por ser errado, mas por dar origem a interpretações equivocadas.

O modo formal, que é a expressão da própria sintaxe, enquanto método de análise metalinguística, nos proporciona uma forma para expressarmos corretamente nossas sentenças fazendo referência aos próprios termos, não aos objetos que pertencem a outro nível. Com isso, podemos reafirmar, seguindo Carnap (1963c, p.59), a tese de que o método da sintaxe lógica, que possibilita a análise da estrutura formal da linguagem como um sistema de regras, é o método próprio da filosofia.

\section{Estrutura linguística e empirismo}

Contudo, dadas as implicações da aceitação de uma linguagem unificada e relativizada a um framework, é possível compatibilizar tal linguagem com o empirismo? No texto de 1963c (p.58), Carnap afirma: "em estreita relação com o fisicalismo, se encontra a tese da unidade da ciência" e "a existência de um sistema único de linguagem, no qual cada termo científico tenha conteúdo, implica, todavia, que todos estes termos pertençam a gêneros logicamente conectados". É evidente, não apenas nesse texto, a preocupação de Carnap para evitar qualquer compromisso ontológico, mantendo sua posição de neutralidade. Enfim, se aceitamos a postura empirista de Carnap, bem como sua teoria lógico-linguística de significado, de que modo podemos acomodar as leis teóricas, uma vez que estas não podem ser deduzidas ${ }^{11}$ das leis empíricas? Este é um problema que preocupou Carnap até seus últimos dias. Tal problema está diretamente relacionado ao critério empirista de significado e à construção de uma linguagem científica unificadora. O problema é que a linguagem proposta por Carnap pode apresentar limitações quanto à significatividade dos termos teóricos, por isso sua preocupação em construir uma linguagem empirista estendida, com termos lógicos e termos não-lógicos divididos em dois vocabulários ( $L_{o} \& L_{t}$, onde $L_{o}=$ linguagem observacional e $L_{t}=$ linguagem teórica), mais as regras de correspondência que relacionam o vocabulário teórico com o vocabulário observacional.

Uma questão levantada por Glymour (1980, p.10) nos ajuda a entender a relevância e as implicações do problema que estamos tratando: "Como podem as evidên- 
cias construídas em uma linguagem confirmar hipóteses em uma linguagem que vai além da primeira (outstrip)?”. Não seria este um problema fundamental para o empirista que assume que a base do conhecimento é dada pela linguagem observacional, formada por sentenças protocolares? Essas questões estão diretamente relacionadas com o problema da significatividade empírica das entidades teóricas, pois os empiristas aceitam que o teste de uma teoria é feito através do confronto entre enunciados de evidência (também podemos chamá-los de enunciados de controle: enunciados deduzidos da teoria em teste) e uma base empírica convencional. Portanto, eles têm de dar conta da relação entre enunciados observacionais e enunciados teóricos, visto que os enunciados do primeiro tipo pretendem, em última instância, confirmar (interpretar parcialmente) os enunciados do segundo tipo, pertencentes à teoria.

Assim, em "Empirismo, Semântica e Ontologia", Carnap se preocupa, especificamente, com o problema das entidades inobserváveis. Este, realmente, é um problema de grande relevância, uma vez que a ciência só estaria livre de compromissos ontológicos se pudesse livrar-se de todas as entidades suspeitas ${ }^{12}$ e, como sabemos, as entidades matemáticas, assim como as propriedades designadas pelos predicados, desempenham uma função fundamental nas teorias científicas. ${ }^{13}$ A questão está, portanto, centrada no tratamento dado por Carnap a partir de uma concepção que analisa a relação interna de um sistema científico, sem eliminar tais entidades.

Carnap não se propõe a discutir a controvérsia (metafísica) entre realistas e idealistas. A justificação que ele apresenta é que a própria controvérsia (linguística) se fundamenta numa discussão metafísica. Também sabemos da preocupação carnapiana em aceitar uma linguagem teórica $\left(L_{t}\right)$, mas que essa faz parte da linguagem total (L) da ciência e se caracteriza pela referência que faz às entidades abstratas, ou postulados teóricos. Nesse caso, a solução apresentada por Carnap se sustenta na possibilidade de estabelecer uma relação entre os termos teóricos e a linguagem observacional, propondo um critério empírico de significado para os termos teóricos, sem assumir um compromisso ontológico (existência no sentido metafísico e diferente do debate realismo - antirrealismo nos termos atuais). As regras de correspondência $(\mathrm{RC})$, que estabelecem uma relação entre a linguagem observacional e a linguagem teórica, são postulados. Isso se deve ao fato de não haver uma interpretação direta e independente para a linguagem teórica; tampouco uma definição. ${ }^{14}$ Assim sendo, o significado da linguagem teórica permanece incompleto. Contudo, a questão que nos interessa é mostrar que a referência aos termos teóricos é feita de modo a não incluir qualquer compromisso ontológico acerca de tais termos enquanto objetos metafisicamente aceitos. A linguagem teórica diz respeito aos termos referentes às propriedades e relações (diretamente) inobserváveis, tais como átomos, elétrons, campos magnéticos etc. Esclarecer a relação desses termos é uma necessidade básica para quem deseja uma linguagem empirista livre de ambiguidades, que sirva de base para a unidade da ciência. Assim sendo, o problema a ser discutido é:

Principia 17(1): 137-164 (2013). 
[...] o problema das condições exatas que os termos e as sentenças da linguagem teórica devem satisfazer para ter uma função positiva na explicação e previsão dos eventos observáveis a serem deste modo aceitáveis enquanto empiricamente significativos. (Carnap 1975b, p.227)

De acordo com Carnap, as tentativas de estabelecer um critério de significado para $L_{t}$ - por exemplo, a tradução de $L_{t}$ em $L_{o}$ - resultaram estreitas demais, dificultando a própria demarcação, daí a aceitação de uma interpretação parcial de $L_{t}$ a partir de $L_{o}$. Devido a essa dificuldade - a impossibilidade de uma tradução direta -, Carnap (1975b, p.235) utiliza regras de correspondência que estabelecem uma relação entre os termos. Essas regras representam um aspecto fundamental na atribuição de significado empírico para $L_{t}$, e "devem ser tais que liguem as sentenças de $L_{o}$ com determinadas sentenças de $L_{t}$ ". Para isso, Carnap assume que as Regras de Correspondência (RC), ou regras-C, são formuladas como postulados, sendo C a conjunção desses postulados de correspondência. Carnap (1975b, p.235) afirma, desse modo, ser possível, a título de exemplo, relacionar o termo teórico 'massa' com o predicado observável 'mais pesado que'. Do mesmo modo, o termo teórico 'temperatura' é relacionado com o predicado observável 'mais quente que'. ${ }^{15}$

Todavia, é importante salientar que o exemplo que Carnap apresenta deve ser visto apenas como uma visão aproximada, de uma forma bastante simples, de relacionar um termo teórico com um termo não-teórico. Se pensarmos, por exemplo, na sensação direta de calor ou frio, provocada pela experiência de tocar um corpo, temos, claro, uma noção de temperatura, mas tal noção é apenas qualitativa. ${ }^{16} \mathrm{Com}$ isso, queremos apenas indicar que um termo teórico não tem seu significado de forma isolada, senão no interior de uma teoria. No caso do termo teórico 'temperatura', outros termos são considerados, como 'massa', 'pressão', 'volume', 'força', a partir de uma teoria, a termodinâmica, por exemplo. Enfim, estamos retomando a seguinte questão: de que modo podemos estabelecer relações entre sentenças observacionais e sentenças teóricas a fim de que as observacionais possam confirmar (testar) as teóricas?

De que forma Carnap enfrenta o problema do significado empírico das teorias científicas, posto que este é um problema central tanto para a unidade da ciência, quanto para uma teoria do significado que pretende a eliminação das controvérsias filosófico-metafísicas? Ainda que Carnap se dedique mais especificamente a este problema a partir de 1935 e 1936, não nos parece, de forma alguma, descabido afirmar que também nos trabalhos anteriores ${ }^{17}$ Carnap já estivesse preocupado com esta questão. Afinal, o verificacionismo era uma tentativa de conferir significado às sentenças teóricas e a sua reformulação, por parte de Carnap, teve como principal motivo as limitações no tratamento dos enunciados universais (e com eles, a (im)possibilidade de verificar leis científicas). Portanto, não há uma completa rejei- 
ção do verificacionismo, pois o que era central no verificacionismo, a relação entre significado e verdade, continua central no confirmacionismo. Poderíamos substituir tanto o termo 'verificabilidade', quanto o termo 'confirmabilidade', pelo termo 'testabilidade', e teríamos como resultado o fato de que o critério de significado continuaria, na sua essência, inalterado.

Deste modo, faz-se necessário ressaltar que a análise do significado de um termo de $L_{t}$ deve ser feita a partir de uma teoria T em que este ocorre. Assim, um critério de significado para $L_{t}$, com base nas regras-C, mostrará se um termo teórico é empiricamente significativo em T, ou carente de significado em T. Além disso, há um aspecto metodológico que deve ser considerado, pois a análise é feita da seguinte maneira: Dada uma sentença empírica significativa $x$ e um termo teórico $y$, então se a ocorrência de $y$ em $x$ produzir uma diferença no evento previsto, $y$ é empiricamente significativo. Do contrário, ele será destituído de significado empírico, porque nenhuma alteração foi observada. Assim, Carnap pretende estabelecer o caráter metodológico dos termos teóricos, bem como sua função em teorias científicas. Essa análise, é claro, exige a descrição de um teste experimental. ${ }^{18}$

A posição de Carnap sobre os termos teóricos pode, portanto, ser chamada de definição operacional. ${ }^{19}$ Os termos teóricos não são tomados de maneira realista, mas como construções que mantêm uma relação funcional no escopo de uma teoria, como instrumento para explicar fenômenos. Deste modo, temos uma forma experimental por meio da qual os termos teóricos podem ser interpretados; não se trata de uma simples tradução. Essa é a noção de operacionalismo - baseada no controle dos fenômenos - que Carnap compartilha com Bridgman. Mas Carnap discorda do operacionalismo de Bridgman no que se refere às definições operacionais: que um termo teórico possa ser completamente definido por meio de regras operacionais. De acordo com Carnap, a definição/interpretação de um termo teórico é sempre incompleta. Na relação entre linguagem observacional e linguagem teórica, as regras operacionais, ou regras de correspondência, são fundamentais, funcionam como um dicionário, ${ }^{20}$ mas a interpretação permanece incompleta para todos os termos teóricos. Além disso, a função das regras de correspondência não é fornecer definições aos termos teóricos, mas possibilitar a correlação destes com os termos observacionais para, então, terem uma interpretação parcial. Permanece, portanto, a possibilidade de introduzir novas regras de correspondência a fim de melhorar a interpretação. Contudo, uma definição completa tornaria um termo teórico em observacional (cf. Carnap 1966, p.238). Para Bridgman (1932, p.5), um conceito pode ser completamente determinado por um conjunto de operações: "um conceito torna-se sinônimo do conjunto correspondente de operações". Assim, um conceito pode ser operacionalmente definido e seu significado encontra-se no uso, ou melhor, nas consequências práticas de seu uso.

Carnap reconhece que o critério é fraco, mas reflete o próprio desenvolvimento

Principia 17(1): 137-164 (2013). 
do empirismo, que foi gradativamente enfraquecendo as formulações do critério de cientificidade. Mesmo assim, é importante ressaltar que o fato de os termos, ou predicados teóricos, não serem diretamente observáveis, não significa que não possam ser testados. O que ocorre é que uma sentença com predicados teóricos é testada de forma indireta, ou seja, a falta de observações diretas é superada através da utilização e aplicação de instrumentos específicos para o caso. Deste modo, uma sentença é confirmável, completa ou incompletamente, se for redutível a uma classe de predicados observáveis (cf. Carnap 1936-7, p.456). Todavia, a confirmação de uma sentença também deve ser entendida como uma confirmação de princípio, ou de possibilidade. Na falta de circunstâncias reais, devemos indicar as condições sobre as quais podemos testá-la. Com isso, temos uma distinção importante entre teste um procedimento efetivo que envolve regras metodológicas — e confirmabilidade — um critério puramente lógico — já que uma sentença pode ser confirmável, sem ser testável. O contrário não é válido. Esta distinção é útil por evitar confusões e, principalmente, por motivar o desenvolvimento das investigações científicas. É desse modo que o assim chamado critério linguístico de significado deve ser entendido; enquanto possibilidade de verificação, confirmação, ou teste de proposições. As proposições, por sua vez, são unidades significativas. O critério é linguístico porque as questões têm como referência uma estrutura linguística L; do contrário elas são incompletas.

Entretanto, a escolha das regras para a formação de $L$ tem de produzir uma linguagem empirista (confirmável), o que é garantido pela decisão de que os predicados descritivos (não-lógicos: que contenham termos teóricos e não-teóricos) de $L$ sejam (intersubjetivamente) testáveis (cf. Decisão I, 1936-7, p.09). Além disso, a visão de Carnap, pautada no princípio de tolerância, nos mostra que a escolha de uma linguagem qualquer não é uma questão de certo ou errado, mas de eficiência em face dos propósitos da prática científica, de tal modo que a linguagem molecular do Aufbau não significa um erro, mas uma limitação do empirismo. Dessa forma, Carnap propõe que o princípio do empirismo seja formulado não como uma asserção (verdadeiro ou falso), mas como uma exigência, ou uma proposta (cf. 1936-7, p.33). No caso da linguagem molecular, linguagem restrita a enunciados moleculares, esta possui a vantagem de ser completamente testável, mas tem como desvantagem o fato de os enunciados de universalidade irrestrita não poderem ser nela expressos. Nesse caso, se tal linguagem for escolhida, o problema que surge é o de como lidar com as leis científicas. Uma possibilidade seria interpretar as leis não como enunciados, mas como regras de inferência de enunciados. É uma questão de escolha, ou de convenção, como afirma Carnap (1936-7, p.20), mas escolher uma linguagem generalizada significa estar mais próximo do que realmente se pratica na ciência.

Deste modo, uma sentença é empiricamente significativa se, sob certas circunstâncias, influenciar a predição de eventos controláveis. Essa é uma medida necessária para a construção de uma linguagem científica nos termos propostos por Carnap, 
pois, assim como a lógica e a matemática desempenham uma função importante no teste de teorias, na explicação e predição de fenômenos, os termos teóricos também são indispensáveis nessas funções. Assim sendo, a construção da linguagem da ciência deve ser devidamente analisada;

Se desejamos construir uma linguagem para a ciência, temos de tomar alguns termos descritivos (i.e. não-lógicos) como termos primitivos. Contudo, os termos podem ser introduzidos não apenas por definições explícitas, mas também por outras sentenças de redução. ${ }^{21}$ (Carnap 1936-7, p.443)

As sentenças de redução, pelas quais os termos teóricos eram introduzidos mediante definições condicionais (1936-7), foram, seguindo o próprio desenvolvimento do empirismo, substituídas por postulados; ${ }^{22}$

'Constructo Teórico' significa certamente o mesmo que 'Termo Teórico' aqui tratado, a saber, termo que não se pode definir explicitamente ${ }^{23}$ nem mesmo numa linguagem observacional estendida, ${ }^{24}$ mas que é introduzido através de postulados e não é completamente interpretado. (Carnap 1975b, p.250)

A incompletude da interpretação e a falta de uma regra de correspondência para cada termo teórico faz com que o problema da significatividade seja relativizado a uma teoria. ${ }^{25}$ Carnap (1975b, p.230) expressa isso da seguinte forma:

\begin{abstract}
Este fato mostra que a especificação, não somente das regras-C, mas também dos postulados ${ }^{26}$ T, é essencial para o problema da significatividade. A definição da significatividade deve ser relativa a uma teoria T, porque o mesmo termo pode ser significativo com relação a uma teoria e não ser significativo com relação a outra.
\end{abstract}

Em An Introduction to the Philosophy of Science (1966), Carnap retoma essa discussão tentando mostrar a importância e a dificuldade de distinguir leis empíricas e leis teóricas a partir da separação de termos observáveis e não-observáveis. A dificuldade deve-se ao fato de haver um contínuo que inicia em observações sensoriais diretas e avança para métodos indiretos de observação, de modo que a separação torna-se arbitrária, ${ }^{27}$ não obstante na prática a distinção funcione e seja extremamente útil (cf. Carnap 1966, p.226).

Sobre o argumento do contínuo, na relação entre 'observacional' e 'teórico', ou entre 'teórico' e 'não-teórico' vale lembrar da importante contribuição de Maxwell (1962, p.7ss), que aponta, exatamente, para o fato de que não podemos contar com um critério que nos habilite a construir uma linha demarcatória a qual não seja, de certo modo, arbitrária. Para Maxwell, requerer uma distinção precisa entre a linguagem observacional e a linguagem teórica é defender um empirismo demasiadamente 
austero, pois não podemos contar com um critério a priori, ou filosófico que possibilite uma separação precisa entre o observável e o teórico. Além disso, aquilo que hoje é tido como inobservável poderá ser observável amanhã, de tal modo que não cometemos nenhum tipo de absurdo lógico ou conceitual se afirmamos a possibilidade de observação direta de um elétron. Podemos, do mesmo modo, supor, afirma Maxwell (p.10), "a descoberta de uma droga que altere o apparatus perceptivo humano, ativando capacidades latentes de tal modo que uma nova modalidade sensível possa emergir. Finalmente, podemos supor que em nosso estado alterado somos capazes de perceber novas entidades". Todavia, o ponto de partida, segundo Maxwell, para a afirmação ou questionamento de qualquer entidade é a aceitação de um 'linguistic framework' que introduza a entidade referida e, nesse caso, quem nos deu a chave para a solução dos problemas relacionados à ontologia foi Carnap em seu clássico artigo "Empiricism, Semantic, and Ontology" (cf. Maxwell, p.22).

Todavia, a distinção entre dois vocabulários, o observacional e o teórico, ainda que arbitrária, é importante, uma vez que a definição e a própria distinção que Carnap faz entre leis teóricas e leis empíricas repousa, exatamente, no fato de estas fazerem, ou não, uso de termos teóricos. No caso das leis empíricas a situação é razoavelmente simples, pois são leis contendo termos observáveis pelos sentidos ou por técnicas não muito complexas, também chamadas de generalizações empíricas. Quanto às leis teóricas, estas são assim chamadas pelo fato de conterem termos teóricos, que denotam entidades como elétrons, prótons etc. Contudo, devemos salientar, uma vez mais, que Carnap não está comprometido com uma posição metafísica, pois as entidades denotadas pelos termos teóricos não possuem autonomia semântica. $\mathrm{O}$ significado se dá em função de uma teoria. E o uso que Carnap faz dos termos teóricos assim como o significado destes deve, na interpretação que estamos propondo, ser relacionado ao problema de explicar o conteúdo empírico das teorias científicas em vez de 'compromissos ontológicos'. A questão, então, é a seguinte: como o vocabulário teórico pode ser interpretado em uma dada teoria científica? Seguimos, nesse caso, a resposta apresentada por Friedman (2012, p.198): “um termo teórico, em particular, é simplesmente um termo introduzido por uma definição implícita, e não tem outro significado além desse". E a própria posição pragmática de Carnap:

Acredito que a questão não deve ser discutida em termos de: "as entidades teóricas são reais"? Mas em termos de: "podemos preferir uma linguagem da física (ou da ciência em geral) que contém termos teóricos, ou uma linguagem sem tais termos"? A partir desse ponto de vista, as interrogações tornam-se uma questão de preferência e de decisão prática. (1966, p.256)

Assim como a interpretação da linguagem teórica é indireta, a justificação das leis teóricas também o é, pois é feita a partir de enunciados empíricos derivados, que por sua vez são testados por enunciados de observação. A posição de Carnap é de que 
as leis teóricas são de fundamental importância para a explicação de leis empíricas e também para a construção e predição de novas leis empiricamente confirmáveis.

\section{Ontologia e convencionalismo semântico}

Retomando o problema dos compromissos ontológicos, Carnap apresenta uma distinção que, segundo ele, resolve a questão, ainda que se utilize de entidades abstratas. A distinção mencionada diz respeito às 'questões internas' e às 'questões externas' de um determinado sistema de referência linguístico (Linguistic Framework), no qual as entidades abstratas são indicadas:

\section{[...] Devemos distinguir dois tipos de questões de existência: em primeiro lugar, as questões da existência de certas entidades do novo tipo no interior do sistema de referência; chamamo-las de questões internas; e em segundo lugar, as questões concernentes à existência ou à realidade do sistema de enti- dade como um todo, chamadas de questões externas. (Carnap 1975a, p.120)}

Deste modo, podemos introduzir novas entidades no domínio de nosso discurso, desde que tais entidades possam ser referidas mediante a construção de uma estrutura linguística e de regras de referência. Isso vale tanto para os sistemas puramente lógicos, quanto para os sistemas empíricos.

As questões internas são formuladas e respondidas no interior do próprio sistema de referências. Em contrapartida, interrogações acerca da existência ${ }^{28}$ do sistema de entidades como um todo fazem parte das questões externas. Para Carnap, o sistema linguístico é o limite sob o qual as entidades podem ter um lugar, desde que sejam devidamente (de modo significativo) referidas por regras estabelecidas que constituem o próprio sistema. Essas regras determinam o que pode e o que não pode ser dito de modo significativo. Portanto, a discussão deixa de ter um caráter ontológico e assume um caráter referencial sustentado apenas por regras.

De posse da distinção feita entre questões internas e questões externas, os problemas que envolviam a controvérsia metafísica podem ser resolvidos, ou melhor, dissolvidos, pois se trata de uma pseudoquestão destituída de significado e conteúdo cognitivo, porque o termo 'real' só pode ser utilizado significativamente enquanto elemento do sistema. A conclusão de Carnap é que as questões internas podem ser respondidas, sejam elas empíricas ou lógicas. Já as questões externas, sobre a existência de um sistema de entidades, são pseudo-enunciados sem valor cognitivo. Todavia, o que pode ser discutido é a aceitação ou não de um determinado sistema, pois envolve uma questão de decisão pragmática: o sistema linguístico é uma questão de escolha entre formas. O que deve ser considerado é a eficácia do sistema. Assim, a escolha de um sistema linguístico é semelhante à escolha de um instrumento. Para 
Carnap, essa é uma decisão puramente prática, já que não necessita de justificação teórica, embora possa ser influenciada pelo conhecimento teórico.

A motivação de Carnap estava em mostrar a possibilidade de construir uma estrutura semântica que fizesse referência a entidades abstratas e que fosse compatível com o empirismo. Nesse texto, fica explícito o uso do 'princípio de tolerância', primeiramente formulado em Logical Syntax of Language, em que Carnap expressa que nós temos completa liberdade sobre as formas linguísticas:

A questão não é fazer proibições, mas chegar a convenções (1934, p.51).

E em "Empirismo, Semântica e Ontologia":

Sejamos prudentes ao fazer asserções e tenhamos uma atitude crítica ao examiná-las, mas sejamos tolerantes ao permitir as formas linguísticas (1975a, p.134).

Nesta obra (1934), Carnap defende amplamente um tipo de convencionalismo linguístico expresso pelo princípio de tolerância: a convencionalidade dos sistemas linguísticos de referência definidos pela escolha das formas de linguagem. Quanto às regras de formação e de transformação de sentenças, que caracterizam a sintaxe lógica, estas podem ser escolhidas arbitrariamente. Qualquer um, afirma Carnap (1934, p.52 e 1963a, p.54-5), pode construir sua própria lógica a partir de regras sintáticas e não de argumentos filosóficos (In logic, there are no morals).

Em conjunção com o princípio de tolerância, devemos explicitar um pouco mais o critério de realidade de Carnap: 'a realidade de alguma coisa nada mais é do que a possibilidade de estar situada em um determinado sistema'. No interior do sistema as questões são decidíveis. O que é indecidível é a controvérsia filosófica sobre a realidade como um todo (conceito não científico), pois para Carnap as questões filosóficas são questões sintáticas ou são pseudoquestões.

O princípio de tolerância representa o convencionalismo carnapiano no que diz respeito às formas linguísticas. Entretanto, o convencionalismo também tem sua importância quando da decisão acerca das sentenças sintéticas. A esse respeito, a análise de Carnap merece uma atenção especial, pois, se de um lado ele aceita a presença do componente convencional, de outro lado ele aponta para a existência de um componente objetivo, não-convencional, eliminando a arbitrariedade.

Para Carnap, a construção de uma linguagem é uma questão puramente convencional, e as regras de inferência podem ser puramente lógicas (L-regras) ou incluir regras físicas (P-regras). Um sistema de linguagem $\mathrm{L}$, constituído a partir de regras de construção e de transformação, é dividido, de acordo com suas consequências, em duas partes. De um lado, estão as L-regras, ou seja, regras lógicas que classificam as sentenças em analíticas ou contraditórias, também chamadas de sentenças logicamente determinadas. De outro lado, estão as sentenças logicamente indeterminadas, 
que dependem de P-regras, ou ainda, de fatos extra-linguísticos — as sentenças sintéticas. Mas, a partir disso, Carnap faz a seguinte afirmação:

É, certamente, possível reconhecer, apenas a partir dessas formas, que uma sentença é analítica; mas só se as regras sintáticas da linguagem forem dadas. Se essas regras são dadas, todavia, então a verdade ou falsidade de certas sentenças sintéticas também pode ser reconhecida apenas a partir de suas formas. (Carnap 1934, p.186)

E conclui dizendo que as P-regras podem ser formuladas em uma via estritamente formal como as L-regras.

A postura de Carnap tem consequências indesejáveis, pois se isso for o caso e nossa interpretação estiver correta, então podemos afirmar que as sentenças sintéticas, estranhamente, podem ser definidas a priori, e o valor de verdade é uma questão puramente convencional. Uma conclusão dessa natureza eliminaria a própria ciência, culminando com um relativismo epistemológico. Entretanto, nessa mesma obra (p.216), Carnap percebe e faz notar que a verdade ou falsidade de uma sentença não pode ser um problema puramente sintático. O princípio de tolerância linguística refere-se somente à livre escolha da estrutura da linguagem e não ao conteúdo das sentenças sintéticas. Carnap enfatiza corretamente a presença do componente nãoconvencional, objetivo no conhecimento dos fatos - a confrontação dos enunciados com os fatos - e afirma que sua posição é oposta ao convencionalismo puro, ou a qualquer teoria coerentista da verdade. De acordo com Carnap (1934, p.317), a sintaxe lógica da linguagem que, entre outras coisas, estabelece a forma de ocorrência dos enunciados cognitivos, não pretende estabelecer qualquer tipo de intervenção na determinação das sentenças protocolares que servem de base de teste para as hipóteses científicas. A determinação das sentenças protocolares não é tarefa da sintaxe lógica, mas dos físicos que observam e fazem protocolos. Uma vez aceitos, tais protocolos podem confirmar ou infirmar uma determinada hipótese em teste. Quanto à aceitação dos resultados, trata-se de uma questão de conveniência e fecundidade. É desse modo que devemos analisar a importância da relação existente entre L-regras e P-regras para a análise de sistemas científicos com conteúdos empíricos.

Deste modo, as leis mantêm o caráter de hipóteses em relação às sentenças protocolares; sentenças da forma de protocolos podem ser L-consequências de leis, mas uma lei não pode ser uma L-consequência de alguma classe finita de sentenças protocolares sintéticas. (Carnap 1934, p.318)

Sobre as sentenças protocolares, é importante ressaltar que Carnap (1934) defende o convencionalismo sem assumir uma tese coerentista. Sua posição é de que as sentenças de teste, definidas empiricamente pelos cientistas, não podem ser estabelecidas de forma conclusiva, mas selecionadas e reexaminadas com o auxílio de 
novas sentenças protocolares que constantemente surgem no processo da investigação científica. Portanto, como afirma Carnap, estas também possuem um caráter hipotético, passível de discussão científica, de modo que a incompatibilidade entre leis e sentenças protocolares, detectada em uma sequência de testes, é afirmada hipoteticamente. Assim sendo, uma lei não pode ser refutada, ou confirmada conclusivamente. Esta mesma posição é defendida em relação aos sistemas formais. As L-regras podem ser revisadas a qualquer momento, assim como as regras que definem um sistema linguístico de referência ${ }^{29}$ — nada é definitivo em ciência. Portanto, afirma Carnap (1934, p.320), "a construção de um sistema físico não é efetuada de acordo com regras fixas, mas por meio de convenções". Todavia, Carnap diz que tais convenções, envolvendo L-regras e P-regras, não são inteiramente arbitrárias, pois são influenciadas por considerações metodológicas pragmáticas. Além disso, as hipóteses devem ser empiricamente controladas. Essa é a posição de um cientista que não pretende alcançar um conhecimento definitivo, mas desenvolver suas hipóteses no sentido de torná-las mais fecundas e resistentes. Esse processo representa o abandono das pretensões de construir o conhecimento sobre uma base segura e incorrigível, rumo a uma interpretação falibilista e correspondentista do conhecimento, sem relativismo.

Entretanto, não parece ser este o entendimento de Friedman e Coffa. Para Friedman (2007, p.10), Carnap adota uma posição holística ${ }^{30}$ no procedimento de teste de teorias. Já Coffa (1995, p.371), afirma o seguinte: "No final, o modo formal de Carnap e o abandono da infalibilidade transformaram a teoria da correspondência em uma teoria da coerência e, desse modo, conduziram o positivismo prescritivo para um descritivismo radical".

Nossa interpretação aponta para o fato de que, talvez, Carnap, ao tratar da função metodológica dos termos teóricos nos limites linguísticos de uma teoria, tenha indicado uma inclinação ao holismo. Tal inclinação também pode ser percebida em duas afirmações: Uma em "The Unity of Science" (p.42), onde Carnap afirma que a ciência é um sistema de enunciados baseados na experiência direta e controlados pela verificação experimental, mas que a verificação não é de enunciados singulares, e sim de um sistema inteiro ou de um subsistema destes enunciados. Outra em Logical Syntax of Language (p.318), ao afirmar o caráter hipotético não apenas das leis, mas também das sentenças singulares, assumindo a impossibilidade de verificação ou falsificação conclusiva das hipóteses, dada a constante possibilidade de erros, mesmo nos enunciados mais básicos. A partir disso, Carnap adverte "é, em geral, impossível testar isoladamente uma sentença hipotética. [...] o teste não se aplica a uma sentença hipotética isolada, mas a todo um sistema de hipóteses". Coffa (1995, p.349) usa essa passagem para afirmar que se ignorarmos a dimensão do convencionalismo semântico, então a posição de Carnap, nesta obra, pode ser caracterizada como uma forma de holismo da linguagem-objeto (object-language holism). Entre- 
tanto, não podemos simplesmente ignorar a função do convencionalismo na definição de uma base empírica, bem como a aplicação do modelo nomológico dedutivo.

De fato, com o uso do modo formal de falar, a linguagem deixa de ser analisada em termos de objetos e estados de coisa, para se referir a enunciados (formas linguísticas) e sua função na relação inferencial com outros enunciados, ou seja, as 'sentenças de pseudo-objetos' do modo material de falar, que têm como referência objetos extralinguísticos, são evitadas. Assim, nenhum enunciado detém uma posição epistemológica privilegiada. Embora Carnap (1949, p.124-5) defende o confronto de enunciados com observações, uma ressalva tem de ser feita: trata-se apenas da primeira operação, dependente da linguagem usada para sua descrição: não há uma interpretação absoluta e independente da escolha de uma linguagem. Também podemos citar outros textos, como, por exemplo, "Testability and Meaning", em que Carnap discute a função das sentenças sintéticas, baseadas na experiência componente objetivo; não convencional ${ }^{31}$ - na confirmação de uma determinada sentença S. O que é convencional, segundo Carnap, é a decisão prática de assumir um determinado grau de confirmação para justificar a aceitação, ou rejeição de $S$ (cf. p.426). Além disso, em "Replies and Systematic Exposition" (1963, p.864), Carnap faz questão de defender o correspondentismo e de negar algum tipo de comprometimento com o coerentismo:

Lá ["Truth and Confirmation", 1936] eu também enfatizei que a primeira operação no teste de enunciados sintéticos é a confrontação do enunciado com os fatos observados. Desse modo, assumi uma posição claramente oposta a um convencionalismo puro e a qualquer teoria coerentista da verdade. Minha discussão tinha implicitamente a intenção de corrigir algumas formulações de Neurath, mas não suas próprias idéias. Ele costumava afirmar que enunciados deveriam ser comparados apenas com enunciados, e não com fatos. Essas formulações eram enganadoras porque pareciam representar, contra as intenções de Neurath, uma concepção coerentista da verdade. Elas foram, de fato, repetidamente interpretadas nesse sentido, não apenas por outsiders como Russell e Ayer, mas também por Schlick. Neurath rejeitou veementemente tal interpretação em discussões do Círculo de Viena e também em uma observação em sua intervenção no Congresso de Paris em 1935 (Erkenntnis, V, 1936, 400). De qualquer modo, não pode haver nenhuma dúvida que Neurath ${ }^{32}$ jamais sustentou essa concepção. E menos ainda ela pode ser atribuída a mim ou aos "fisicalistas" em geral, como críticos têm algumas vezes feito.

\section{Conclusão}

A importância da rejeição da metafísica no compromisso de Carnap rumo à 'filosofia científica' deve-se, essencialmente, ao fato de que os conceitos metafísicos não po-

Principia 17(1): 137-164 (2013). 
dem ser definidos ou constituídos de acordo com o sistema construcional. O sistema construcional não contradiz a metafísica simplesmente porque as divergências são próprias do domínio metafísico. A teoria construcional se mantém em posição neutra sobre tais disputas por considerá-las indecidíveis ou, usando uma expressão de Carnap (1928a, §5) "uma ociosa disputa linguística”. Daí a importância de superar a filosofia especulativa rumo à filosofia científica ou, melhor dizendo, à lógica da ciência (cf. Friedman 2012, p.191).

Segundo Friedman, Carnap, sobretudo em sua concepção madura de teorias científicas, alcança uma posição claramente neutra. Tal posição deve ser vista como uma tentativa de dissolver (muito mais que resolver) as disputas ontológico-metafísicas. "Realistas e instrumentalistas têm encontrado dificuldade para entender (muito menos aceitar) a visão desenvolvida por Carnap sobre termos teóricos, que estabelece uma posição neutra ${ }^{33}$ entre realismo e instrumentalismo" (2011, p.249). Devemos, portanto, buscar o terreno firme da ciência e abandonarmos de vez as confusões linguísticas da filosofia tradicional. E, acompanhando Carnap, da própria epistemologia (incluindo sua primeira grande obra: Aufbau) que mistura componentes lógicos com componentes psicológicos. ${ }^{34}$

Enfim, devemos evitar as obscuras, ociosas e indecidíveis disputas filosóficas em nome de questões importantes, como as que Carnap aponta no último parágrafo de seu último livro:

\begin{abstract}
Alguns físicos acreditam que há uma boa chance de um novo avanço em um futuro próximo. Se será em breve ou mais tarde, deveremos confiar — providenciando que líderes estadistas mundiais detenham-se da última loucura de uma guerra nuclear e permitam à humanidade sobreviver - que a ciência continuará a fazer progresso e levar-nos-á a insights cada vez mais profundos na estrutura do mundo. (1996, p.291-2)
\end{abstract}

O que resta, então, à filosofia? ${ }^{35}$ A resposta de Carnap nos foi dada há muito tempo, em sua Logical Syntax of Language (1934, p.279): "uma vez que a filosofia for purificada de todos os elementos não científicos, apenas a lógica da ciência permanece". Permanece enquanto metateoria científica ou, se quisermos preservar o nome da filosofia, enquanto filosofia científica. Mas alguém poderia, ainda assim, insistir com suas dúvidas: Por que filosofia científica? Qual o real significado empregado por Carnap? Sinônimo de ciência exata ou de metateoria? Talvez Carnap não tenha sido tão claro sobre isso, dificultando uma resposta direta e simples sobre sua concepção de filosofia. Segundo Kienzler (2012, p.81), Carnap não nos deu uma versão final e detalhada de sua visão sobre esse tópico. Quando questionado sobre o uso do termo 'filosofia científica', em uma entrevista de 1964 (Interview mit Rudolf Carnap, 1964) ele nos dá um extrato de sua posição:

Principia 17(1): 137-164 (2013). 
Eu não estou certo se esse é o melhor termo, mas nós frequentemente o usamos, e acredito que ele tenha alguma justificação. Naturalmente, não deve haver um mal-entendido como se a filosofia fosse científica e pudesse usar o mesmo método e tivesse o mesmo conteúdo da ciência. Há uma clara diferença: A tarefa da ciência é investigar fatos sobre a natureza, organizá-los e compará-los para, então, explicá-los e etc., e assim nos dar um retrato do mundo. A filosofia, por outro lado, não deve invadir o campo da ciência. As vezes, os filósofos têm feito isso, mas penso que isso é injustificado. (Carnap 1964. In Kienzler 2012, p.81)

Nossa conclusão é que à filosofia científica cabe a análise lógica da linguagem das ciências naturais ou, simplesmente, da ciência unificada; um método. Portanto, uma perspectiva analítica e empirista (uma análise científica das ciências empíricas): só há dois tipos de proposições significativas, as analíticas e as empíricas e isso é tudo. Se continuarmos a utilizar o termo 'filosofia', ele certamente não terá seu significado usual de filosofia especulativa. ${ }^{36}$

\section{Referências}

Ayer, A. J. 1952. Language, Truth and Logic. New York: Dover Publication (ed.). 1959. Logical Positivism. New York: The Free Press. 1959a. Editor's Introduction. In: Ayer 1959, p.3-28. . 1959b. Verification and Experience. In: Ayer 1959, p.228-246.

Boyd, R. 1981. Scientific Realism and Naturalistic Epistemology. In: P. Asquith; R. Giere (orgs.). PSA 1980, vol. 2. East Lansing: Philosophy of Science Association, p.613-662.

- 1985. The Logician's Dilemma: Deductive Logic, Inductive Inference and Logical Empiricism. Erkenntnis 22: 197-252.

Bridgman, P.W. 1932. The Logic of Modern Physics. New York: The Macmillan Company.

Carnap, R. 1928a. The Logical Structure of the World. Berkeley e Los Angeles: University of California Press.

- 1928b. Pseudoproblems in Philosophy. Berkeley e Los Angeles: University of California Press.

- 1930. The Old and The New Logic. In: Ayer 1959.

- 1932a. The Unity of Science. Bristol: Thoemmes Press.

—. 1932c. On Protocol Sentences. Noús 21: 457-470. In: Sarkar 1996.

- 1934. The Logical Syntax of Language. New Jersey: Littlefield, Adams Company.

- 1936-7. Testability and Meaning. Philosophy of Science 3: 01-40; 4: 420-471.

-1938. Logical Foundations of the Unity of Science. In: International Encyclopedia of Unified Science. Chicago: University of Chicago Press.

- 1942. Introduction To Semantics. Cambridge, Mass.: Harvard University Press.

—. 1949 [1936]. Truth and Confirmation. In: H. Feigl; W. Sellars (eds.) Reading in Philosophical Analysis. New York: Appleton-Century-Crofts.

- 1950. Logical Foundations of Probability. Chicago: The University of Chicago Press.

- 1952. Quine on Analyticity. In: Carnap 1990.

Principia 17(1): 137-164 (2013). 
- 1952b. Meaning Postulates. In: Carnap 1956a.

- 1956a. Meaning and Necessity. Chicago: The university of Chicago Press.

_. 1958. Observation Language and Theoretical Language. In: Hintikka 1975.

- 1959a [1932]. The Elimination of Metaphysics Through the Logical Analysis of Language. In: Ayer 1959, p.60-81.

—. 1959d [1932]. Psychology in Physical Language. In: Ayer 1959.

- 1960. The Aim of Inductive Logic. In: Nagel 1960.

—. 1963a. Intellectual Autobiography. In: Schilpp 1963.

—. 1963b. Replies and Systematic Exposition. In: Schilpp 1963, p.859-1013.

—. 1963c [1935]. Filosofía Y Sintaxis Lógica. México: Universidad Nacional Autónoma.

- 1966. An Introduction to the Philosophy of Science. New York: Basic Books, Inc.

—. 1967 [1934]. On The Character of Philosophic Problems. In: R. Rorty (ed.) The Linguistic Turn. Chicago: The University of Chicago Press.

—. 1975a [1950]. Empirismo, Semântica e Ontologia. São Paulo: Abril Cultural.

—. 1975b [1956]. O Caráter Metodológico dos Conceitos Teóricos. São Paulo: Abril Cultural.

—. 1975c [1955]. Significado e Sinonímia nas Linguagens Naturais. São Paulo: Abril Cultural.

Carnap, R.; Quine, W.V. 1990. Dear Carnap - Dear Van: The Quine-Carnap Correspondence and Related Work. Edited, With an Introduction by Richard Creath. Berkeley: University of California Press.

Carus, A. W. 2007. Carnap and Twentieth-Century Thought. New York: Cambridge University Press.

Cirera, R. 1994. Carnap and the Vienna Circle: Empiricism and Logical Syntax. Amsterdam Atlanta: Rodopi.

Coffa, J. A. 1995. The Semantic Tradition from Kant to Carnap. Cambridge: Cambridge University.

Creath, R. 2012. Before Explication. In: Wagner 2012.

Da Costa, N.C.A.; French, S. 2003. Science and Partial Truth: A Unitary Approach to Models and Scientific Reasoning. Oxford: University Press.

Dutra, L. H. de A. 2005. Oposições Filosóficas: A Epistemologia e suas Polêmicas. Florianópolis: Editora da UFSC.

Earman, J. (ed.). 1992. Inference, Explanation, and Other Frustrations: Essays in the Philosophy of science. Berkeley: University of California Press.

- 1993. Carnap, Kuhn, and the philosophy of scientific methodology. In: Horwich 1993.

Feigl, H. 1963. Physicalism, Unity of Science and the Foundations of Psychology. In: Schilpp 1963.

- 1970. The 'Orthodox' view of theories: remarks in defense as well as critique. Minesota Studies in the philosophy of science IV. Minneapolis: University of Minesota Press, p.3-16.

French, S. 2008. The Structure of Theories. In: Psillos 2008.

- 2009. Ciência: Conceitos-Chaves em Filosofia. Porto Alegre: Artmed.

Friedman, M. 1991. The Re-Evaluation of Logical Positivism. Journal of Philosophy 88: 505519.

Principia 17(1): 137-164 (2013). 
1992. Philosophy and the Exact Science: Logical Positivism as a Case Study. In: Earman 1992.

-1999. Reconsidering Logical Positivism. Cambridge: University Press.

- 2007. Carnap's Revolution in Philosophy. In: M. Friedman; R. Creath (eds.) 2007.

- 2011. Carnap on Theoretical Terms: Structuralism Without Metaphysics. Synthese 180: $249-263$.

- 2012. Rational Reconstruction, Explication, and the Rejection of Metaphysics. In: Wagner 2012.

Friedman, M.; Creath, R. (eds.). 2007. The Cambridge Companion to Carnap. Cambridge: Cambridge University Press.

Glymour, C. 1980. Theory and Evidence. Princeton: Princeton University Press.

Goodman, N. 1963. The Significance of Der Logische Aufbau der Welt. In: Schilpp 1963.

Hempel, C. G. 1935. On The Logical Positivists' Theory Of Truth. In: Sarkar 1996.

Horwich, P. (ed.). 1993. World Changes. Cambridge: MIT Press.

Irzik, G.; Grunberg, T. 1995. Carnap and Kuhn: Arch-Enemies or Close Allies? The British Journal for the Philosophy of Science 46(3): 285-307.

Kienzler, W. 2012. Carnap's Conception of Philosophy. In: Wagner 2012.

Kuhn, T. 1969 [1962]. A Estrutura das Revoluções Científicas. São Paulo: Perspectiva.

Liston, G. 2012. Carnap e o Revisionismo. Principia 16(1): 99-119.

- 2013. O Holismo Fisicalista de Neurath: uma atocrítica do positivismo lógico. Dissertatio 37: 47-67.

Maxwell, G. 1962. The Ontological Status of Theoretical Entities. In: H. Feigl; G. Maxwell (eds.) Minnesota Studies of Philosophy of Science. Minneapolis: University of Minnesota Press, p.3-15.

Neurath, O. 1983. Philosophical Papers 1913-1946. Ed. and transl. by Robert S. Cohen \& Marie Neurath, (Vienna Circle Collection vol. 16). Dordrecht: Reidel.

Oberdan, T. 1993. Protocols, Truth and Convention. Amsterdam - Atlanta: Editions Rodopi.

— 1996. Postscript to Protocols: Reflections on Empiricism. In: R. Giere; W. A. Richardson (eds.) 1996.

- 1998. Discussion: The Vienna Circle's 'Anti-Foundationalism'. British Journal for the Philosophy of Science 49: 297-308.

- 1999. Discussion: Deconstructing Protocols: Reply to Uebel. British Journal for the Philosophy Science 50: 301-304.

Planck, M. 1945. Treatise on Thermodynamics. New York: Dover Publications.

Psillos, S. 2000. Rudolf Carnap's 'Theoretical Concepts in Science'. Studies in History and Philosophy of Science 31(1): 151-172.

Psillos, S.; Curd, M. (eds.). 2008. The Routledge Companion to Philosophy of Science. New York: Routledge.

Quine, W. V. 1985a. Dois Dogmas do Empirismo. São Paulo: Nova Cultural.

Reisch, G. 1991. Did Kuhn kill Logical Empiricism?.Philosophy of Science 58(2): 264-277.

Richardson, W. A. 1998. Carnap's Construction of the World. Cambridge: University Press.

Rosen, G. 2012. Abstract Objects. In: N. E. Zalta (ed.) The Standford Encyclopedia of Philosophy.

Schlick, M. 1988 [1934]. O Fundamento do Conhecimento. São Paulo: Abril Cultural.

Schillp, P. A. (org.). 1963. The Philosophy of Rudolf Carnap. La Salle: Open Court.

Principia 17(1): 137-164 (2013). 
Stadler, F. (ed.). 2003. The Vienna Circle and Logical Empiricism: Re-Evaluation and Future Perspectives. Dordrecht: Kluwer Academic Publishers.

- 2003. What is the Vienna Circle? Some Methodological and Historiographical Answers. In: Stadler 2003.

Stadler, F; Nemeth, E. (eds.). 1996. Encyclopedia and Utopia: The Life and Work of Otto Neurath (1882-1945). Dordrecht: Kluwer Academic Publishers.

Uebel, T. (ed.). 1991. Rediscovering the Forgotten Vienna Circle. Austrian Studies on Otto Neurath and the Vienna Circle. (Boston Studies in the Philosophy of Science), Dordrecht: Kluwer.

— 1992. Overcoming Logical Positivism From Within. Amsterdam - Atlanta: Editions Rodopi B. V.

- 1996. Anti-Foundationalism and the Vienna Circle's Revolution. British Journal for the Philosophy of Science 47: 415-440.

- 1999. Discussion: Protocols, Affirmations, and Foundations: Reply to Oberdan. British Journal for the Philosophy of Science 50: 297-300.

- 2012. The Bipartite Conception of Metatheory and the Dialectical Conception of Explication. In: Wagner 2012.

Van Fraassen, B.C. 1980. The Scientific Image. Oxford: Claredon Press.

- 2002. The Empirical Stance. New Haven: Yale University Press.

- 2006. A Imagem Científica. São Paulo: Unesp/Discurso Editorial.

Wagner, P. (ed.). 2012. Carnap's Ideal of Explication and Naturalism. London: Palgrave Macmillan.

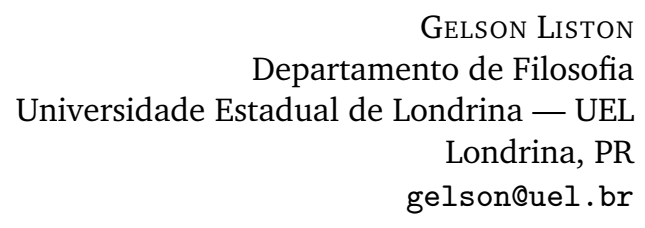

Resumo. Neste artigo, retomamos a obra carnapiana com o objetivo de reavaliar um período da filosofia da ciência cuja influência ainda pode ser notada nos trabalhos atuais de orientação empirista e que, portanto, não pode simplesmente ser arquivado à títulos de pesquisa histórica ou de nostalgia literária. Avaliaremos a leitura proposta pelos revisionistas de Carnap, em especial a leitura de Friedman e concluiremos afirmando uma posição minimalista de Carnap em relação à filosofia, identificada com a lógica da ciência e preocupada com a interpretação empirista da linguagem científica.

Palavras-chave: Carnap; Friedman; revisionismo; filosofia da ciência; empirismo.

\section{Notas}

${ }^{1}$ Mesmo aceitando as limitações da chamada 'visão recebida'(Received View) da filosofia da ciência do positivismo lógico, sobretudo a desenvolvida por Carnap, que ressalta a tese de que as teorias científicas são formuladas de modo axiomático, em linguagem lógica contendo

Principia 17(1): 137-164 (2013). 
dois vocabulários: o vocabulário observacional (Vo) e o vocabulário teórico (Vt), algumas posições de van Fraassen parecem ser um claro exagero retórico de um empirista que pertence à tradição empirista de Carnap. Podemos citar mais um exemplo do que chamamos de exagero retórico de van Fraassen com a seguinte afirmação: "A principal lição da filosofia da ciência do século XX pode bem ser a seguinte: nenhum conceito que seja essencialmente dependente de linguagem possui qualquer importância filosófica que seja" (2006, p.109). De acordo com da Costa and French (2003, p.22), a interpretação semântica de van Fraassen, com seus modelos teóricos, sugere que as teorias científicas podem ser vistas como entidades 'extralinguísticas'. Contudo, tal posição enfrenta a seguinte dificuldade: Que noção/definição de 'verdade' van Fraassen utiliza sem uma caracterização linguística? Sobre a relação 'linguagem e teoria de modelos' cf. da Costa and French 2003, p.34. Mesmo que van Fraassen mantenha uma posição agnóstica em relação a qualquer compromisso ontológico que ultrapasse os limites da observabilidade, ele não nega que as teorias científicas possam ter um valor de verdade; não afirma que tais teorias seriam meros instrumentos. Com a abordagem semântica, o conceito de adequação empírica é reconstruído de modo que uma teoria é empiricamente adequada se é verdadeiro o que ela diz sobre observáveis, ou se "possui algum modelo tal que todas as aparências sejam isomórficas a subestruturas empíricas daquele modelo" (van Fraassen 2006, p.122). Em nossa visão, em uma análise formal da linguagem, sintaxe e semântica se complementam, de modo que priorizar uma abordagem (sintaxe), ou outra (semântica), é uma questão pragmática, visto que ambas necessitam de uma estrutura linguística para serem expressas. Em termos lógicos, a diferença da abordagem sintática em relação à abordagem semântica está no modo em que se apresenta uma teoria científica: enunciando seus axiomas (abordagem sintática), ou construindo seus modelos (abordagem semântica).

${ }^{2}$ Friedman (2011, p.251) sugere que, talvez, tenha faltado paciência, por parte de van Fraassen, ao analisar a abordagem carnapiana sobre o conteúdo empírico das teorias científicas. Segundo Friedman, a abordagem proposta por van Fraassen 1980 não é tão diferente (se não a mesma) da defendida por Carnap. Na visão semântica de van Fraassen, uma teoria é identificada com uma classe de estruturas, seus modelos. É conhecida a crítica de van Fraassen à interpretação sintática de Carnap, assim como a distinção entre duas linguagens com seus vocabulários teórico e observacional. Contudo, aceitar uma teoria como empiricamente adequada, de acordo com o empirismo construtivo de van Fraassen, é afirmar que há algum modelo dessa teoria, em suas subestruturas empíricas, que de alguma forma 'corresponde ao mundo'. Na sequência desse artigo, analisaremos a visão sintática de teorias cientificas, proposta por Carnap, considerando três pontos: (i) uma teoria científica é um sistema axiomático parcialmente interpretado (received view); (ii) a distinção entre a linguagem teórica e a linguagem observacional é arbitrária, e (iii) a linguagem observacional é teoricamente contaminada, seus enunciados não estão livres de pressupostos teóricos.

${ }^{3}$ Sobretudo no que diz respeito à superação do 'sensorialismo' pós Aufbau (nos referimos à tese de que os conceitos científicos poderiam ser explicitamente definidos a partir de uma base de conceitos observacionais, pressupondo, talvez, uma distinção clara entre o vocabulário teórico e o vocabulário observacional) e na formatação (enquanto gênese) do debate Realismo - Antirrealismo científico.

${ }^{4}$ Não estamos negando, todavia, a possibilidade de um período fundacionalista na obra carnapiana, sobretudo nos trabalhos que antecedem o livro de 1934, Logical Syntax of Language

Principia 17(1): 137-164 (2013). 
(cf. Liston 2012).

${ }^{5}$ Logical Syntax of Language, p.51.

${ }^{6}$ Uma vez mais ressaltamos aqui - a título de exemplo apenas, pois nosso propósito não é avaliar as teses de van Fraassen - uma diferença crucial entre a posição de Carnap (received view) e a de van Fraassen (empirismo construtivo). Van Fraassen critica que a divisão entre duas linguagens, uma teórica e outra não-teórica era puramente filosófica, feita de fora. Tal concepção, aquela da 'visão sintática', implicava uma definição errônea do conteúdo empírico de uma teoria, sendo ele definido filosoficamente. Uma alternativa a esta concepção é apresentada pelo empirismo construtivo, no qual o conteúdo empírico de uma teoria é definido pela própria ciência, assim como a distinção entre o observável e o inobservável (distinções intracientíficas): os limites da observabilidade são demarcados teoricamente, o que pode sugerir uma saída naturalista de van Fraassen (cf. van Fraassen 2006, p.149). Talvez isso seja apenas um vestígio de naturalismo, já que van Fraassen vê na epistemologia a grande responsável pelas discussões sobre a aceitação e crença, o que nos leva a imaginar que van Fraassen não atribui à epistemologia o mesmo status cognitivo das ciências empíricas. Todavia, parece possível afirmar que van Fraassen naturaliza o problema da observabilidade. Sobre isso, cf. Dutra 2005, p.119.

${ }^{7} \mathrm{Na}$ história, contada por Carnap, quando os dois geógrafos (cientistas) ultrapassam o limite (critério empírico-científico) eles deixam de usar o conceito 'interno' de existência e a discussão passa a ter como referência o conceito 'externo' metafísico.

${ }^{8}$ Sobre o realismo científico, cabe aqui o seguinte esclarecimento: Conquanto o realismo científico, em alguns aspectos (como assumir a existência de entidades inobserváveis como entidades reais), se aproxime das discussões metafísicas, o principal problema no realismo científico não é metafísico, isto é, a existência do mundo exterior que é o que Carnap rejeita como problema filosófico (questão externa). Os autores envolvidos no debate sobre o realismo científico têm um problema diferente, que podemos denominar "ontológico" (ainda que o termo 'metafísica' às vezes seja utilizado por eles mesmos): os termos que utilizamos para falar de coisas correspondem a entidades reais? Que tipo de crença está envolvida na aceitação de uma teoria científica? Para uma discussão atualizada sobre o debate realismo antirrealismo, cf. da Costa and French 2003, cap. 8 e French 2009, caps. 7 e 8.

${ }^{9}$ Como exemplo de uma pseudo questão ou o que Carnap chama de "uma questão disfarçada sob a forma de uma questão teórica, enquanto que de fato se trata de uma questão não teórica" podemos citar o sistema dos números. A partir da construção de um sistema de referência para os números naturais, por exemplo, podemos responder analiticamente a questões do tipo 'existe um número primo maior do que cem?' Por outro lado, uma questão de natureza puramente filosófica do tipo 'os números existem?' gera controvérsia exatamente pela falta de uma estrutura linguística de referência, pois tomada como questão externa, não apresenta respostas, mas apenas discussões infindáveis (cf. Carnap 1975a, p.116ss). Nota-se que a aceitação de um sistema linguístico de referência não implica a crença na realidade das entidades.

${ }^{10}$ Com a utilização do modo formal de falar, a linguagem é entendida como um cálculo a partir do qual as questões podem ser resolvidas. Esse acréscimo pode ser apresentado como uma das diferenças do empirismo lógico em relação ao empirismo moderno, sobretudo o de Hume.

11 Tampouco reduzidas à leis empíricas.

Principia 17(1): 137-164 (2013). 
${ }^{12}$ Carnap (1975a, p.113) utiliza o termo 'entidades suspeitas' tanto para as entidades abstratas quanto para as entidades ou termos teóricos. Contudo, nossa preocupação é discutir a relação entre o vocabulário teórico e o vocabulário observacional.

${ }^{13}$ A distinção entre entidades (abstratas e concretas; observáveis e inobserváveis) e termos (teóricos e não teóricos) é de fundamental importância na filosofia contemporânea (cf. Rosen 2012). Assim como o é a interpretação parcial dos termos teóricos na tradição empirista do positivismo lógico, especialmente a de Carnap. Ainda que não tenhamos uma delimitação precisa, seguiremos de perto a distinção proposta por Van Fraassen (2006, p.36) ao examinar, primeiramente, os erros categoriais envolvidos na distinção entre teoria e observação: "Essas expressões, 'entidade teórica' e 'dicotomia observável-teórico', tomadas literalmente, são exemplos de erros categoriais. Termos ou conceitos são teóricos (introduzidos ou adaptados para as finalidades da construção de teorias); as entidades são observáveis ou inobserváveis". ${ }^{14}$ Em um sentido estrito, as Regras de Correspondência não são definições e sempre é possível introduzir novas regras, aumentando a interpretação da linguagem teórica (cf. Carnap 1966, p.236-7). Além disso, não contamos com uma linguagem observacional neutra, já que toda sentença observacional é teoricamente contaminada, impossibilitando, portanto, uma distinção absolutamente clara entre as duas linguagens. Reafirmamos, com isso, que a delimitação é, em sentido estrito, arbitrária, dada a natureza dos constructos teóricos. Esse aspecto será retomado nas próximas páginas.

${ }^{15}$ Contudo, devemos lembrar que a utilização do modo formal de falar, no processo de reconstrução racional, evita o uso de conceitos vagos e muitas vezes subjetivos, como é o caso do conceito de sensação térmica, e privilegia o uso de conceitos quantitativos mais precisos, como é o caso do conceito temperatura, em termos de graus, mas que também pode encontrar seu limite no caso de temperaturas extremas. De acordo com Carus (2007, p.20), a reconstrução racional proposta por Carnap é um processo iterativo de substituição de conceitos vagos por conceitos mais precisos até alcançar o conceito de explicação: a substituição do conceito explicandum pelo conceito explicatum.

${ }^{16}$ De acordo com a Parte I do Treatise on Thermodynamics de Max Planck, notamos que "a sensação direta não fornece nenhuma medida científica quantitativa do estado de um corpo no que diz respeito ao calor. [...] Para propósitos quantitativos, utilizamos a mudança de volume que acontece em todos os corpos quando aquecidos sob pressão constante" (1945, p.1).

${ }^{17}$ Ver, por exemplo, o § 2 do artigo "The Elimination of Metaphysics Through the Logical Analysis of Language". Nele, Carnap trata do significado de um termo e, resumindo, afirma que um termo adquire significado através da redução às assim chamadas 'sentenças de observação' ou 'sentenças protocolares'.

${ }^{18}$ Sobre este ponto, vale conferir o exemplo de Maxwell (1962, p.5) que trata da interpretação de um termo teórico enquanto uma 'conveniente ficção' ou como 'termo genuíno', que, por sua vez, possui uma função explicativa.

${ }^{19}$ Operacional, no sentido de que o significado de um termo teórico é dado mediante as relações de aplicação experimental.

${ }^{20}$ Carnap (1966, p.233) afirma que o uso do termo ‘dicionário', proposto por Norman Campbell, enquanto analogia, é um nome sugestivo para o conjunto de regras de correspondência. Um dicionário Inglês-Português, por exemplo, relaciona termos de uma linguagem natural com termos de outra linguagem natural. Contudo, a relação entre termos teóricos e ter-

Principia 17(1): 137-164 (2013). 
mos observacionais, via conjunto de regras, é um pouco mais complexa, sobretudo tendo em vista que "a 'linha' que separa observáveis de não observáveis é altamente arbitrária" (Carnap 1966, p.226).

${ }^{21} \mathrm{O}$ conceito temperatura, por exemplo, pode ser introduzido pelas seguintes sentenças de redução: "Se um termômetro está em contato com um objeto $x$, então $T(x)=c$ se, e somente se, o termômetro registra $c$ graus" (Hempel 1959, p.120). Nota nossa.

22 Os postulados teóricos contribuem na atribuição de significado aos termos teóricos (interpretação parcial); na introdução dos termos teóricos e na determinação do conteúdo factual de uma teoria (cf. Carnap 1958, p.82).

${ }^{23}$ Esses termos não podem ser explicitamente definidos a partir de termos não-teóricos. Nota nossa.

${ }^{24}$ A linguagem observacional estendida (L'o) compreende a linguagem observacional com a adição dos termos disposicionais "Dsr" expressáveis em $L_{o}$ a partir da especificação de um procedimento de teste para a disposição Dsr, onde: 's' é a relação estabelecida e ' $r$ ' é o resultado esperado (cf. Carnap 1975b, p.242ss). Nota nossa.

${ }^{25}$ No limite poderíamos afirmar que Carnap relativiza também o significado das sentenças empíricas tendo em vista que (i) toda tentativa de tradução ou redução implica, em algum sentido, mudança de significado e (ii) toda sentença observacional está teoricamente contaminada. Em Truth and Confirmation (1949, p.125) Carnap afirma que "ao se traduzir de uma linguagem para outra, o conteúdo factual de um enunciado empírico nem sempre pode ser mantido sem alteração. Tais alterações são inevitáveis se as estruturas das duas linguagens diferem em aspectos importantes. Por exemplo: enquanto muitos enunciados da física moderna são completamente traduzíveis a enunciados da física clássica, isso não ocorre, ou só ocorre de forma incompleta, como outros enunciados". Tomando isso isoladamente, poderíamos, obviamente, afirmar que Carnap antecipa algumas teses de Kuhn, sobretudo a respeito da incomensurabilidade (cf. Earman 1993; Reisch 1991; Irzik and Grunberg 1995). Todavia, não podemos negligenciar a importância do componente não convencional e objetivo no conhecimento dos fatos, ressaltado por Carnap, como veremos adiante (seção 4). Questionamentos foram levantados sobre se a posição de Kuhn representa uma alternativa à Received View ou simplesmente uma continuidade, com outro foco: o sociológico. Nossa posição é que de acordo com a concepção carnapiana de filosofia da ciência, certamente o livro de Thomas Kuhn (1962) A Estrutura das Revoluções Científicas não é um trabalho representativo dessa área. Tanto é que Carnap nunca o citou. Embora não tenha tido muitas oportunidades, é verdade, mas o nome de Thomas Kuhn não aparece em seu último e importante trabalho de 1966; An Introduction to the Philosophy of Science.

${ }^{26}$ Os postulados teóricos, ou T-postulados contêm apenas termos teóricos; as regras-C, ou C-postulados, contém ambos os termos. A conjunção dos dois forma, o que Carnap chama de TC, ou seja; $\mathrm{TC}\left(t_{1} \ldots, t_{n} ; o_{1} \ldots, o_{m}\right)$. Nota nossa.

${ }^{27}$ Um termo pode ser teórico para um filósofo e não-teórico para um físico.

$28 \mathrm{O}$ conceito 'existência' só possui significado enquanto conceito científico. Neste sentido, só podemos afirmar a existência de algo enquanto elemento do sistema linguístico. Portanto, não podemos utilizá-lo significativamente ao próprio sistema.

${ }^{29}$ Carnap 1963b, p.921, considera também a alteração de uma estrutura linguística por outra, constituindo uma alteração radical, ou seja, a "transição de uma linguagem $L_{n}$ para uma nova linguagem $L_{n+1}$ ".

Principia 17(1): 137-164 (2013). 
${ }^{30}$ Essa posição também é defendida por Creath (2012, p.163), ao afirmar, em uma de suas teses (tese 6), que o empirismo de Carnap é holista.

${ }^{31}$ E mesmo em Logical Syntax of Language, p.41, Carnap diz que na interpretação material uma sentença sintética pode ser verdadeira, quando certos fatos existem, ou falsa, e conclui: Sentenças sintéticas são os enunciados genuínos sobre a realidade.

${ }^{32}$ Sobre a posição de Carnap em relação à suposta vinculação de Neurath com a teoria coerentista da verdade, pensamos que Neurath pode e deve ser defendido contra a acusação de que sua teoria coerentista leve a um relativismo radical, mas não em relação à própria teoria coerentista da verdade (nota nossa; cf. Liston 2013).

${ }^{33}$ Carnap assume, assim, uma forma de neutralismo em relação ao debate realismo - idealismo. Para ele, o conflito é puramente linguístico, sobretudo no que diz respeito à utilização significativa ou não do conceito 'existência'.

${ }^{34}$ Cf. Friedman 2007, p.12.

${ }^{35}$ Essa é a posição minimalista que Carnap assume em relação à filosofia enquanto lógica da ciência.

${ }^{36}$ Parte deste artigo é resultado do projeto de pesquisa de pós-doutorado, realizado na University of Leeds, UK. Agradeço ao prof. Steven French pelos comentários e supervisão de estágio e à CAPES, pelo apoio financeiro.

Principia 17(1): 137-164 (2013). 